\title{
Wisdom Safety Monitoring System Based on Risk Map and Location Service
}

\author{
Xiaoyu Wang ${ }^{1 *}$, Xiongjun Yuan ${ }^{2}$ and Jun Liu ${ }^{2}$ \\ ${ }^{1}$ Changzhou Vocational Institute of Engineering, Changzhou; 213164, China \\ ${ }^{2}$ Changzhou University, Changzhou; 213164, China \\ ${ }^{*}$ Corresponding author
}

\begin{abstract}
To construct Wisdom Safety Supervision and Emergency System (WSSES), it is necessary to solve the three key issues include that the risk prediction based on the regional hazards, the safety information based on the location service, and the wisdom technologies for the emergency-assisted decision. In this study, the WSES based on the big data, cloud computing and internet was introduced was designed and implemented. The system adopts the combination of software and hardware and $B / S$ architecture. According to theory of modern safety management theory, it has the functions of real-time information collection and processing, quantitative risk analysis and assessment, accident scene simulation and display on GIS. So that the three key issues troubled safety supervision and management departments were solved: the regional hazards predicted by risk cloud map, the location based safety information acquired by real-time monitor, and the wisdom emergency-assisted decision provided by the Artificial intelligence system. The system is applicable to the safety supervision and management business of government safety supervision departments as well as the safety management of high-risk industries such as petrochemical industry and other industrial areas.
\end{abstract}

Keywords-risk map; location service; wisdom safety; emergency response; decision support system

\section{INTRODUCTION}

In recent years, a few accidents reveal the weaknesses of the construction of safety supervision and management information system. For example, on August 12, 2015, a fire and explosion at Tianjin Ruihai Dangerous Goods Depot caused 165 deaths, 8 missing, 798 injured, 304 buildings, 12,428 commercial vehicles and 7,533 containers damaged, the direct economic loss approved over 6.866 billion yuan ${ }^{[1]}$.

The accident exposed a series of safety regulatory loopholes and weaknesses, at least the following three aspects of torture safety supervision and management capabilities and scientific level: if we can predict the type of hazardous chemicals and the extent of accumulation, we can take prior control measures, control the danger sources, and reduce the loss in the accidents; if we can predict location of the accident area, determine the number of people in the area and maintain contact with them, we can promptly notify fire staff to avoid unnecessary of the casualties and sacrifices; if we can create intelligent hazardous chemicals emergency response system and make emergency decisions quickly and accurately, we can response quickly, so as to avoid the spread and expansion of accidents.
One of the three issues is the risk prediction based on regional hazards, and the other is collection and analysis of safety supervision and management Information on location based service (LBS), the third is the emergency rescue decision based on smart city safety Support system. Only these problems solved, can we fundamentally enhance the capability of emergency response and greatly reduce the loss of accidents. If the answers to these three questions can be further displayed on the GIS platform, the supervision and management of dangerous sources will be clearer and more intuitive, and the emergency rescue of accidents will be more convenient and efficient.

There is a certain amount of research on these three issues. Maroš Lacinák *, Jozef Ristvej ${ }^{[2]}$ put forward the concept of smart city and analyzed its characteristics of "safe city". They believes that big data and cloud computing are the core of smart and safe cities. However, there is no detailed discussion on how to support big data and cloud computing Smart Safety City specific programs. Ming Zhao Xiang Liu ${ }^{[3][4]}$ designed and implemented a tool for facilitating the process of urban regional risk assessment, built a geoprocessing workflow models for severity calculation, vulnerability evaluation and risk mapping respectively, then integrate these models into an automatic GIS tool, and apply it in a typical urban district of north China to demonstrate its functionalities and utility. Omar Valverde-Arias ${ }^{[5]}$, used geographical information system (GIS) tools to generate a drought risk map (DRM) for rice cropping in Babahoyo Canton, Ecuador, this map represents production risks incurred through the onset of a drought event based on the interaction between vulnerability and threat. However, none of these studies provide a dynamic, real-time display of the source of danger and therefore they do not reflect the actual state of safety regulation or the timing of an accident.

The idea and practice of solving these problems in this paper is to construct Wisdom Safety Supervision and Emergency System(WSSES) based on risk cloud image and LBS with the support of big data, cloud computing and internet of things.

\section{IDEAS AND CONCEPTS OF WSSES}

\section{A.Ideas of WSSES}

Based on risk management theory ${ }^{[6]}$, WSSES forms a system of safety management, accident prevention and early warning through the establishment of dynamic information database and monitoring database, emergency plan, accident model database and historical accident database of hazard 
information sources, So that emergency disposal of production safety events can be scientifically and intuitively supported by decision-making; WSSES supports the communication and interaction of various communication modes of video, voice, text and data among command centers, on-the-spot command vehicles, emergency monitors, rescue workers and remote experts to ensure the unobstructed communication, So that the emergency command of production safety events can obtain an effective communication and command platform; WSSES can provide a wizard-based event processing flow and record all the data of video and voice information from the accident reporting, preparation, command, rescue, rehabilitation, analysis to the termination, and automatically generate accident cases Text, provide a true and vivid reference for future incident disposal analysis.

\section{B. Concept of WSSES}

The concept of safety first, comprehensive supervision, initiative prevents. Strengthen safety supervision system, corporate responsibility system, publicity, training and education system and emergency rescue system. Through the refinement of safety management tasks and responsibilities, the implementation of safety management, safety inputs, staff skills training, emergency rescue drills, so that the system function of initiative to eliminate hidden dangers, prevent accidents and correctly handle the accident can be achieved.

The concept of safety management standardization, intelligent, simple. The system takes the national security information as the standard to ensure the uniformity, sharing and portability of the data. The system cooperates with the sensor hardware that collects information in real time and management system software to real-time monitoring the key points and key areas, so that the problem of people cannot gather information or make false information artificially is solved. The system is easy to operate, simple steps, publishing content refined for the user, to ensure system availability, stability and security.

\section{IMPLEMENTATION PROGRAM}

\section{A. Technical Support}

The architecture of WSSES is a combination of hardware and software by $\mathrm{B} / \mathrm{S}$. In which the hardware includes: the information collection port such as remote sensing, infrared, microwave, optical fiber, and wireless communication etc., information transmission facilities, data processing platform, integrated application network, medium data storage and processing equipment. Software technologies include: GIS technology, database construction and processing technology, computer communication technology, 4G technology, virtual reality technology, multimedia technology, and security monitoring information collection technology.

\section{B. System Architecture and Cloud Platform}

The system applies the latest information technologies such as cloud computing, big data and mobile Internet and mobile explosion-proof hardware terminals (explosion-proof smart phones, explosion-proof tablet computers, smart cards, etc.) to the safety supervise and manage process, adopted the information collection method suitable for the production process environment, realized the long-distance communication, the data modeling, the intelligence analysis. Its support platform and technical features shown in Figure 1, Figure 2.

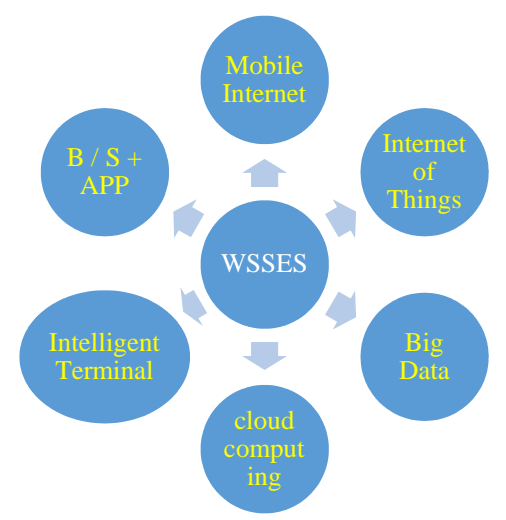

FIGURE I. WSSES SYSTEM STRUCTURE

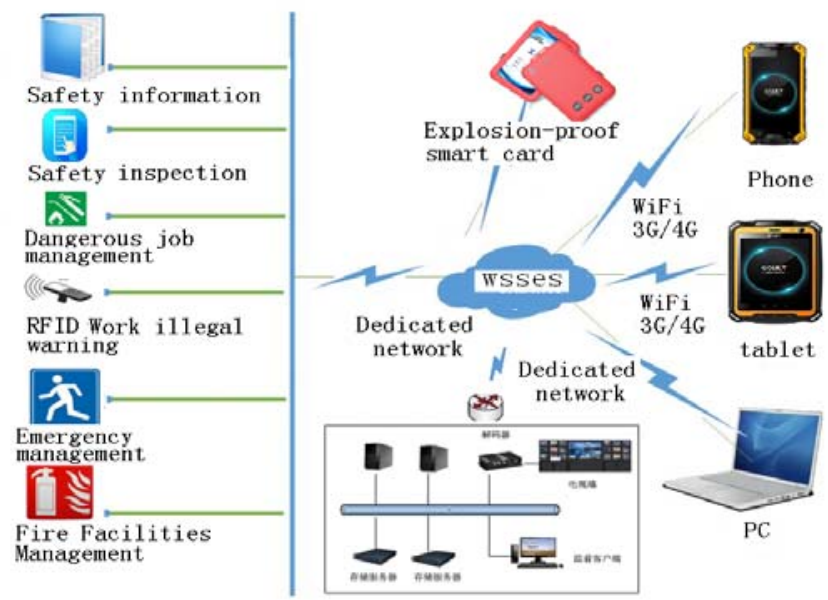

FIGURE II. WSSES SYSTEM CLOUD PLATFORM

\section{System Framework}

The system is composed of two subsystems: the government safety supervision end and the enterprise end. Through the dynamic association between the two subsystems, the government can supervise and manage the safety of all enterprises in the region, the enterprises can carry out safety management within themselves and the safety information can be exchanged between the government and the enterprises. All of the Subsystem has the background + APP technical support, so the phone can be used for remote login and operation of the system, shown in Figure 3. 


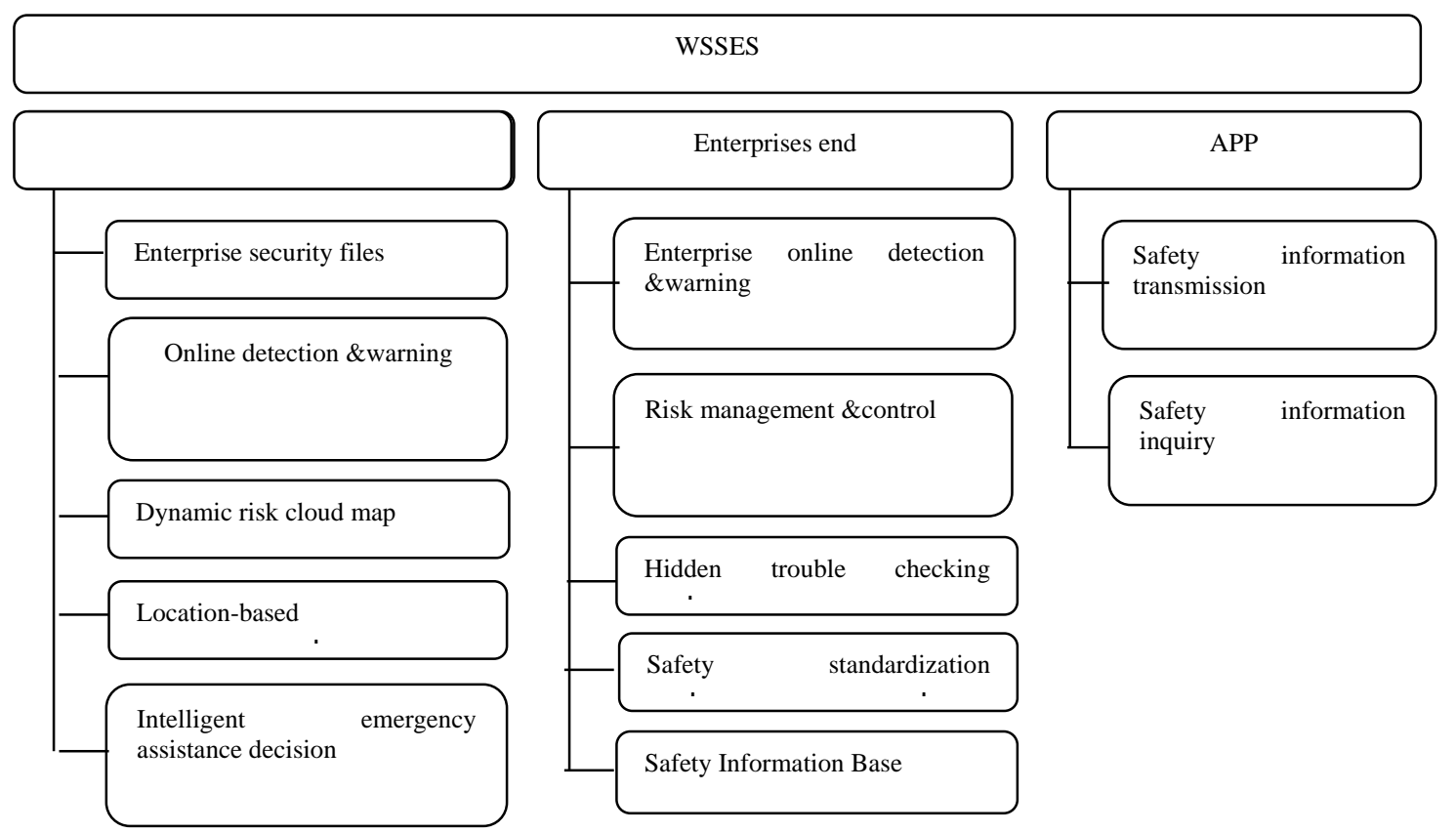

FIGURE III. SYSTEM LOGIC FRAMEWORK

In the system a variety of data acquisition hardware as the data input, server, room facilities, large screen display system, platform workstations, duty workstations and other hardware as the basis, the two are connected by the $4 \mathrm{G}$ network straightly. See Figure 4.

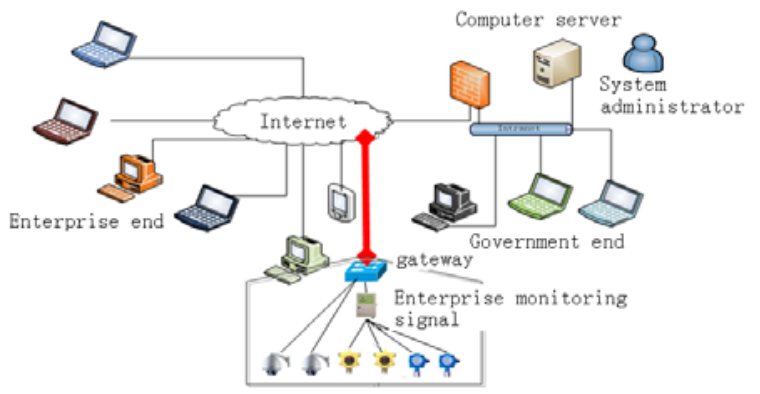

FIGURE IV. SYSTEM TOPOLOGY

\section{KEY TECHNOLOGY SOLUTIONS}

\section{A. Dynamic Risk Assessment and Risk Cloud Mapping Technology}

The dynamic risk assessment and cloud map technology of WSSES is to collect real-time safety management and technical information about operators, equipment and facilities, production materials, mobile hazard sources (vehicles, ships, etc.) and working environment to the system data cloud platform. In the wisdom of the model library support quantitative risk assessment, location-based dynamic and static risk overlay data processing. Geographic platform on the color, real-time, dynamic display of the degree of risk in each region for the safety supervision department to provide risk warning, risk analysis and provide a scientific basis for risk supervision. The data processing logic shown in Figure 5.

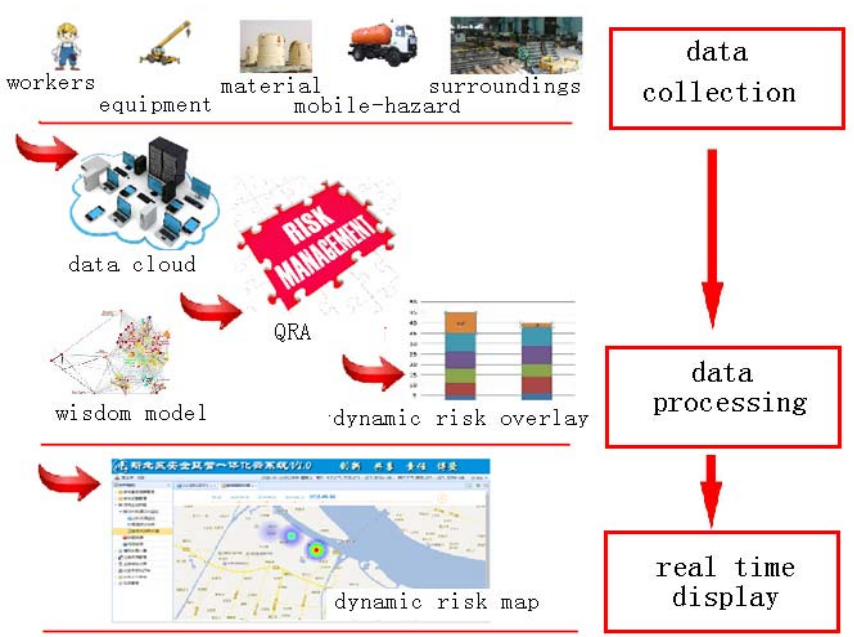

FIGURE V. INHERENT RISK CLOUD DATA PROCESSING LOGIC

\section{B. Location Based Services (LBS) Security Management Technology}

Location Based Services (LBS), also known as Location Services, is an information management technology that obtains the location and status information of mobile terminals through positioning technology and realizes various location-related business services.

The system of LBS collects relevant location and status information through regional operators, safety inspectors, dangerous operators, production equipment, dangerous chemicals transport equipment, accident process and consequence simulation calculation module, and transmits the information to the system data cloud platform. With the support of the intelligent model library, data processing is performed, and the location information of the security 
locations in each area is displayed in color, real time and dynamically on a geographic platform. Thus, personnel counting, regional risk assessment, warning everyone in dangerous area and emergency rescue scheduling can be quickly realized. The data processing logic shown in Figure 6.

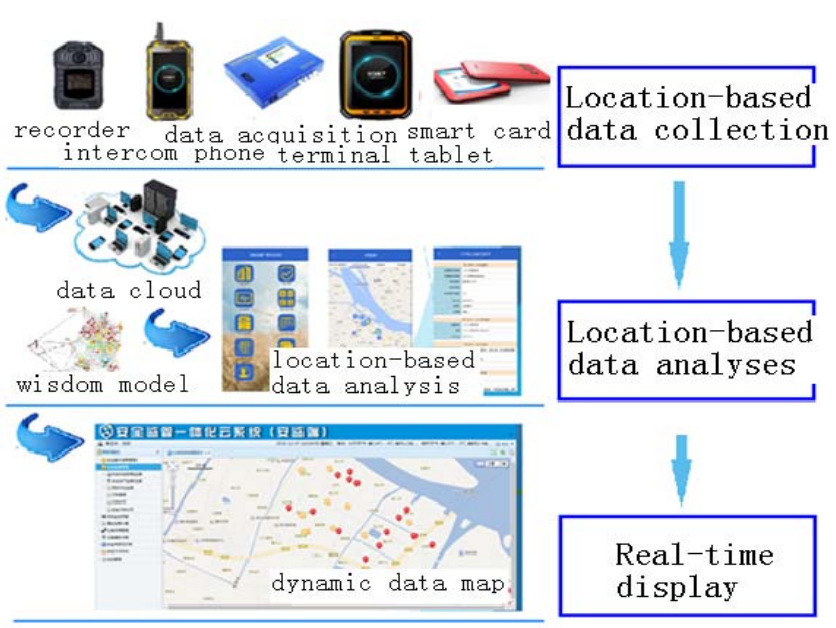

FIGURE VI. LBS SAFETY MANAGEMENT DATA PROCESSING LOGIC

\section{Intelligent Emergency Assistance Decision-Making Technology}

Accurate and timely grasp of the accident, the impact of regional and development trends, rapid and correct implementation of rescue measures is the key to emergency response. The system calls accident identification, material characteristics and emergency disposal data in the data cloud platform according to the information of the accident source item, and simulates the accident scene with the support of the intelligent model library to determine the area and the development trend of the accident. The emergency routes are displayed on the geographic platform and the complete emergency document text is provided, through the Internet platform the intelligent terminal emergency response program is send. This program includes the calculation results of accident consequences, evacuation routes, emergency resource dispatching, emergency experts and on-site emergency response technologies. It can provide auxiliary decision-making and technical support for emergency rescue of safety supervision departments. See Figure 7.

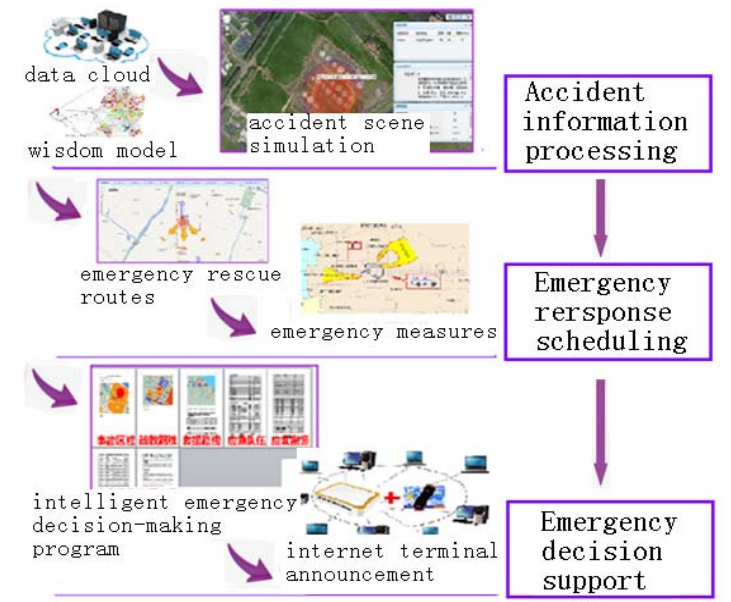

FIGURE VII. INTELLIGENT EMERGENCY DECISION SUPPORT PROGRAM DATA PROCESSING LOGIC

\section{EXAMPLE}

Since 2016, the system has been successfully used in a chemical park in Jiangsu, China, which has improved the government's safety supervision and management and informational and scientific level of production safety management in the park. Figure $8 \sim$ Figure 12 for the system operation interface.

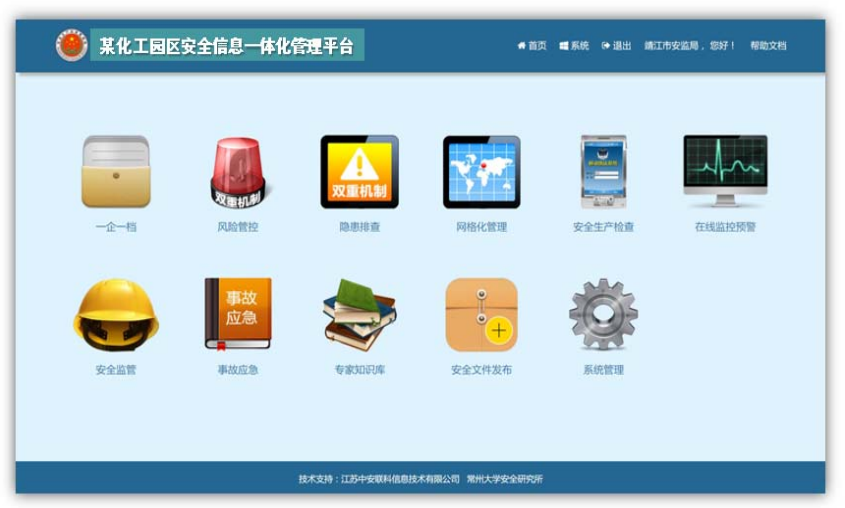

FIGURE VIII. SYSTEM MAIN INTERFACE

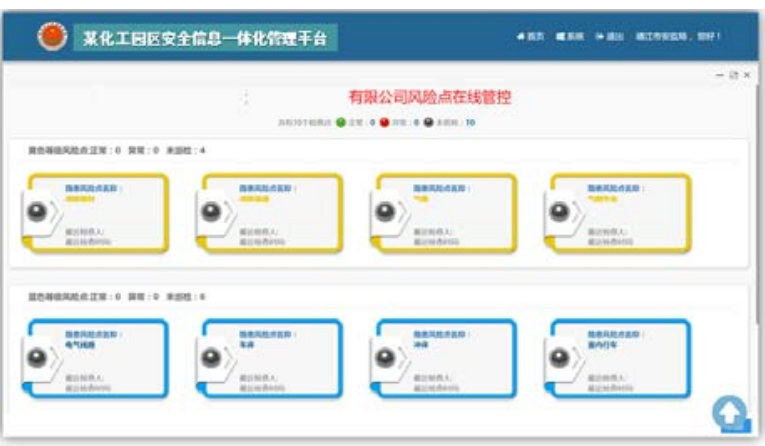

FIGURE IX. HAZARD MONITORING IMPLEMENTATION 


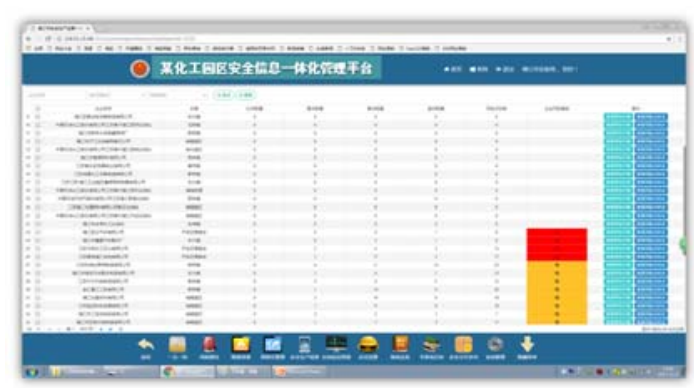

(a)

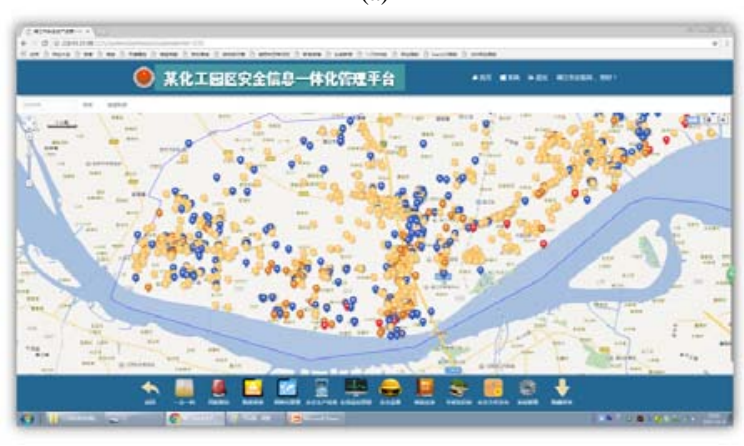

(b)

FIGURE X. RISK STATISTICS AND CLOUD MAP

a. Risk Statistics Analysis $\quad$ b. Risk Point Distribution

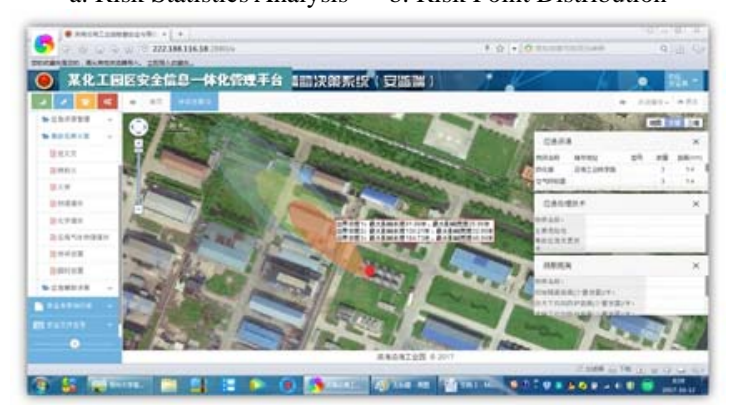

FIGURE XI. ACCIDENT SIMULATION AND EMERGENCY RESCUE

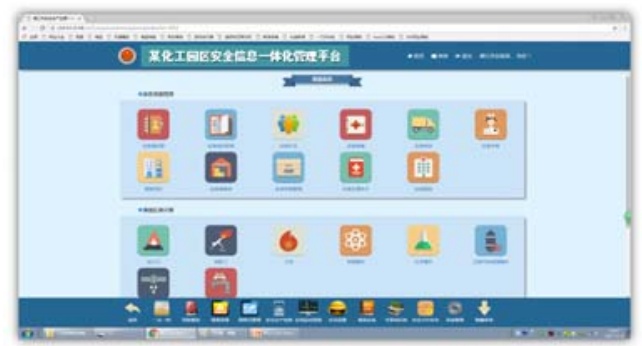

(a)

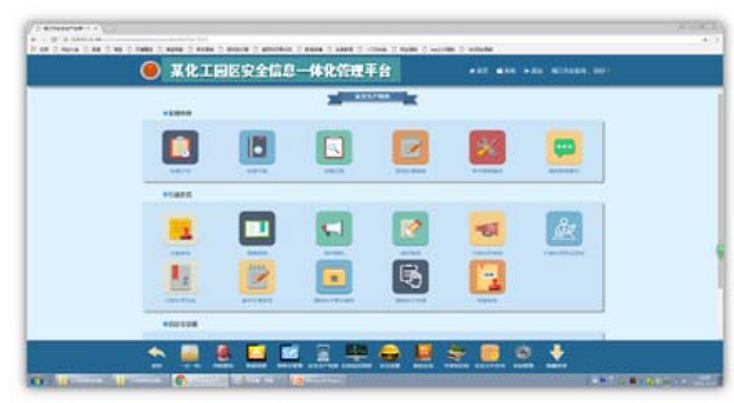

(b)

FIGURE XII. RESOURCE MANAGEMENT AND INFORMATION TRANSMISSION

a. Emergency Resource Management $\quad$ b. Safety Information Transmission

\section{CONCLUSION}

This paper discusses the safety monitoring system based on the theory of modern safety management. Taking risk analysis and assessment and accident simulation technology as a support, the big data cloud system as a platform, the system integrates hardware and software to solve the three key issues troubled safety supervision and management departments were solved: the regional hazards predicted by risk cloud map, the location based safety information acquired by real-time monitor, and the wisdom emergency-assisted decision provided by the Artificial intelligence system. The application of a chemical park in Changzhou has proved that the system is applicable to the safety supervision and management of government as well as to the safety management of high-risk industries such as chemical industry, petrochemical industry, oil and gas storage and transportation.

At present, China is embarking on a new wave of information construction and a new market opportunity for the construction of production safety information, which provides potential customer resources for the success of this system. With the continuous improvement of science and technology and the continuous improvement of safety requirements, WSSES will continuously improve and develop.

\section{References}

[1] Investigation report of the State Council, Tianjin Port "8 • 12" Ruihai dangerous goods warehouse accident investigation report of particularly serious fire and explosion. Central government portal .www.gov.cn, 2016-02-05.

[2] OmarValverde-AriasaAlbertoGarridoabJosé

L.ValenciacAna MaríaTarquis, Using geographical information system to generate a drought risk map for rice cultivation: Case study in Babahoyo canton (Ecuador). Biosystems Engineering.Available online 1 September 2017.In Press, Corrected Proof.

[3] MingZhao, XiangLiu, Reprint of: Regional risk assessment for urban major hazards based on GIS geoprocessing to improve public safety.Safety Science.Volume 97, August 2017, Pages 112-119.

[4] MingZhao,XiangLiu, Development of decision support tool for optimizing urban emergency rescue facility locations to improve humanitarian logistics management.Safety Science.Volume 102, February 2018, Pages 110-117.

[5] OmarValverde-Arias, Smart city, Safety and Security. ScienceDirect.Procedia Engineering 192 (2017) 522 - 527.

[6] E.BorgonovoaV.CappellibF.MaccheroniaM.Marinacci, Risk analysis and decision theory: A bridge,European Journal of Operational Research, Volume 264, Issue 1, 1 January 2018, Pages 280-293. 